\title{
Chromobox homolog 2 protein: A novel biomarker for predicting prognosis and Taxol sensitivity in patients with breast cancer
}

\author{
WANG YANG CHEN ${ }^{1,2}$, XIAN YU ZHANG ${ }^{3}$, TONG LIU $^{3}$, YANG LIU ${ }^{3}$, YA SHUANG ZHAO ${ }^{4}$ and DA PANG ${ }^{3}$ \\ ${ }^{1}$ Heilongjiang Academy of Medical Sciences, Harbin, Heilongjiang 150044; ${ }^{2}$ Department of Cancer Epidemiology, \\ Institute of Cancer Prevention and Treatment, Harbin Medical University; ${ }^{3}$ Department of Breast Surgery, \\ The Affiliated Tumor Hospital of Harbin Medical University, Harbin, Heilongjiang 150081; ${ }^{4}$ Department of Epidemiology, \\ Public Health College, Harbin Medical University, Harbin, Heilongjiang 150040, P.R. China
}

Received March 5, 2015; Accepted November 10, 2016

DOI: $10.3892 / \mathrm{ol} .2016 .5529$

\begin{abstract}
Polycomb group (PcG) complexes modify histones to silence tumor suppressor genes, which exhibit an important function in tumorigenesis and progression. The chromobox (Cbx) protein family is a critical component of PcG-mediated repression. $\mathrm{Cbx} 2$, a member of the $\mathrm{Cbx}$ protein family, is hypothesized to exhibit a vital role in breast cancer. In the present study, immunohistochemical analysis using tissue microarrays was performed to determine the levels of $\mathrm{Cbx} 2$ protein expression in breast cancer. The association between Cbx 2 expression and the clinical features and prognosis of 455 breast cancer patients was analyzed. In addition, the efficacy of Taxol was evaluated by comparing the survival of patients with high or low Cbx 2 expression. The results revealed that $\mathrm{Cbx} 2$ expression was higher in cancer tissues compared with adjacent normal tissues. Furthermore, high Cbx 2 expression was significantly associated with large tumor size, lymph node metastasis, high TNM stage and positive human epidermal growth factor receptor-2 (HER-2) status. Patients with high Cbx 2 expression also exhibited a shorter mean overall survival (OS) time (74.37 months) compared with patients with low Cbx2 expression (77.37 months). Univariate analysis indicated that high $\mathrm{Cbx} 2$ expression increased the risk of mortality by 1.826 -fold compared with low Cbx 2 expression [hazard ratio (HR), 1.826; 95\% confidence interval $(\mathrm{CI}), 1.069-3.116 ; \mathrm{P}=0.027]$. Among patients
\end{abstract}

Correspondence to: Professor Yashuang Zhao, Department of Epidemiology, Public Health College, Harbin Medical University, 157 Baojian Street, Harbin, Heilongjiang 150040, P.R. China E-mail: zhao_yashuang@263.net

Professor Da Pang, Department of Breast Surgery, The Affiliated Tumor Hospital of Harbin Medical University, 150 Haping Road, Harbin, Heilongjiang 150081, P.R. China

E-mail:pangda@ems.hrbmu.edu.cn

Key words: chromobox2, chromobox protein, breast cancer, Taxol, survival with high Cbx2 expression, the mean OS time of individuals treated with Taxol (71.01 months) was lower compared with patients that had not received Taxol treatment (78.43 months; log-rank test statistic, 13.03; $\mathrm{P}<0.001)$. However, no significant difference in OS time was identified in the low expression group. The results of the current study revealed that $\mathrm{Cbx} 2$ may present a novel biomarker for predicting the prognosis of breast cancer patients. Cbx 2 may also represent a potential target for treatment due to its important function in Taxol treatment responses.

\section{Introduction}

Breast cancer is the most common type of cancer among women worldwide, accounting for $29 \%$ of novel cancer cases in 2014 (1). A total of 39,620 breast cancer mortalities were reported among women in 2013 in the USA despite constant breast cancer incidence (2). Considering the heterogeneity of breast cancer, diverse terms have been used to explain the underlying biological and pathological characteristics, responses to therapy and clinical outcomes (3). The molecular mechanisms of carcinogenesis are complex due to aberrant protein expression, gene changes and miRNA deregulation. Therefore, numerous studies have focused on screening for novel diagnostic and prognostic biomarkers and therapeutic targets in breast cancer (4-6).

Polycomb group (PcG) complexes mediate the inherent stability of cells. These proteins regulate the expression of numerous genes that control the maintenance, differentiation and proliferation of adult stem cells and cancer cells (7). Biochemical characterization has categorized PcG complexes into two subtypes: Polycomb repressive complex (PRC) 1 and PRC2 (8-10). The chromobox (Cbx) family comprises five members (Cbx2, Cbx4, Cbx6, Cbx7 and Cbx8) in mammals (11), and it is a component of PRC1. Numerous studies have indicated that the Cbx family is associated with cancer. High $\mathrm{Cbx} 7$ expression has been found to associate with ovarian clear cell adenocarcinoma, lymphomagenesis and gastric cancer (12-14). Cbx4 exerts a critical function in tumor angiogenesis by controlling the hypoxia-inducible factor- $1 \alpha$ protein (15). However, the association between Cbx2 expression and cancer remains unclear. Recent evidence has 
confirmed that the overexpression of $\mathrm{Cbx} 2$ results in the differentiation and exhaustion of hematopoietic stem cells (16). Notably, a number of malignant tumors with normal gene copy numbers demonstrate recurrent $\mathrm{Cbx} 2$ overexpression (17).

In the present study, $\mathrm{Cbx} 2$ protein expression was analyzed by immunohistochemistry (IHC) using tissue microarrays (TMAs) in an independent cohort of patients with breast cancer. Furthermore, the association between $\mathrm{Cbx} 2$ expression and the clinicopathological features, survival and chemotherapy outcomes of breast cancer patients were analyzed. The aim of the study was to determine whether $\mathrm{Cbx} 2$ presents a potential prognostic marker and alternative therapeutic target in breast cancer.

\section{Materials and methods}

Patients and clinical samples. A total of 455 patients primarily diagnosed with breast cancer, who underwent surgery at The Affiliated Tumor Hospital of Harbin Medical University (Harbin, China) between March and December in 2006, were consecutively recruited for the present study. None of the patients had received any treatment prior to surgery. All patients were pathologically diagnosed with invasive ductal cancer according to the World Health Organization classification of breast tumors (18) and the median age of patients was 49 years (range, 25-78 years). Patients with a previous history of tumors, including recurrent tumors, metastatic disease and bilateral tumors, and patients who had previously received neoadjuvant treatment were excluded. A total of 455 tumor tissue specimens and 216 corresponding adjacent normal tissues located $5 \mathrm{~cm}$ from the cancer margin were archived from the Department of Pathology at the Affiliated Tumor Hospital of Harbin Medical University. A total of 216 paired tumor and normal breast tissues and 239 unpaired tumor tissues were collected for further study. Patient information regarding tumor size, pathological grade, lymph node status and chemotherapy treatment were obtained from medical records. Among the 309 patients with complete records of adjuvant chemotherapy regimen, 7 accepted Taxol cis-platinum treatment, 13 accepted taxol fluorouracil treatment, 43 accepted Taxol epirubicin treatment, 9 accepted nedaplatin cis-platinum treatment, 10 accepted nedaplatin fluorouracil treatment, 22 accepted nedaplatin epirubicin treatment, 143 accepted fluorouracil epirubicin cyclophosphamide treatment, 28 accepted epirubicin Taxol treatment and 34 accepted more than two regimens. According to regimens including Taxol, patients were split into two groups. One group contained 122 patients who received chemotherapy, including Taxol, and another group contained 187 patients who received chemotherapy without Taxol. All patients provided written informed consent for the use of their clinical specimens for medical research. This study was approved by the research medical ethics committee of Harbin Medical University.

Histology, TMA and IHC. The tissues obtained from surgical removal were rapidly fixed in $10 \%$ neutral buffered formalin. Subsequent to dehydration, clearing, infiltration and paraffin-embedding, the prepared tissue blocks were cut into 4-mm sections for hematoxylin and eosin staining. Three cores ( $2 \mathrm{~mm}$ in diameter) were obtained from each breast cancer sample and inserted into the recipient TMA blocks. A total of 216 invasive ductal carcinomas and corresponding normal breast tissue samples were inserted into three TMA blocks, and 239 unpaired cancer tissues were fixed in two TMA blocks. All TMA blocks were cut with a microtome to 4- $\mu \mathrm{m}$ sections and affixed to a slide treated with $5 \%$ poly-lysine.

Estrogen receptor (ER), progesterone receptor (PR), human epidermal growth factor receptor-2 (HER-2) and tumor protein 53 (p53) expression and Ki-67 were routinely assayed by IHC, as previously described (19). Briefly, IHC staining was performed for ER and PR using 4- $\mu \mathrm{m}$ paraffin sections cut from TMA blocks. ER, PR and HER-2 markers were immunostained in a single process using hematoxylin and eosin stains and the following primary monoclonal antibodies: Mouse anti-human ER (1:100; ZM-0104), mouse anti-human PR (1:150; ZM-0215), mouse anti-human HER2 (1:100; ZM-0065) (Beijing Zhongshan Golden Bridge Biotechnology Co., Ltd., Beijing, China), mouse anti-human Ki-67 (1:100; IR62661; Dako, Glostrup, Denmark) and mouse anti-human p53 (1:400; sc-47698; Santa Cruz Biotechnology, Inc., Dallas, TX, USA) antibodies. Samples were incubated with the primary antibodies overnight at $4^{\circ} \mathrm{C}$, followed by incubation with a biotin-labeled goat anti-mouse immunoglobulin (Ig) G secondary antibody (SP-9002; Beijing Zhongshan Golden Bridge Biotechnology Co., Ltd.) at room temperature for $30 \mathrm{~min}$. Fluorescence in situ hybridization (FISH) assays were performed to determine HER-2 status in tumors with 2+ immunoreactivity according to guidelines (20). Tumor cells were considered to exhibit positive ER and PR expression when $>10 \%$ of the tumor cell nuclei were stained in the three cores. Tumor cells were considered to exhibit HER-2 protein overexpression when $>10 \%$ of cells exhibited strong membrane staining (3+) or positive signals in the FISH tests (21). The $\mathrm{Ki}-67$ score was defined as the percentage of positively stained cells, regardless of the intensity, among the total number of invasive cells in the scored area (22). Positive staining for Ki-67 was defined when $>10 \%$ of stained cells exhibited positivity. For p53, positive staining of $<10 \%$ of tumor cells was defined as negative tumor expression, whereas staining of $\geq 10 \%$ tumor cells indicated positive tumor expression $(23,24)$.

$\mathrm{Cbx} 2$ protein expression was evaluated using immunostained TMA slides from each core. IHC was conducted as follows: Briefly, antigen retrieval was performed using $10 \mathrm{mM}$ sodium citrate $(\mathrm{pH} 6.0)$ and sections were washed with Tris-buffered saline. To block endogenous peroxidase activity, the sections were treated with $3 \% \mathrm{H}_{2} \mathrm{O}_{2}$ for $10 \mathrm{~min}$. Non-specific binding was blocked by incubation with $1 \%$ low lethal serum (Boster Inc., Wuhan, China) in PBS. Next, the slides were incubated with anti-CBX2 polyclonal antibodies (1:300; PA5-309961; Thermo Fisher Scientific, Inc., Waltham, MA, USA) at $4^{\circ} \mathrm{C}$ overnight. The slides were then incubated with goat anti-rabbit IgG secondary antibody (SP-9001; Beijing Zhongshan Golden Bridge Biotechnology Co., Ltd.) at room temperature for $30 \mathrm{~min}$. After washing with PBS three times, each section was treated with $300-500 \mathrm{ml}$ diaminobenzidine working solution at room temperature for 5-10 $\mathrm{min}$ for visualization and then washed with distilled water.

IHC evaluation of Cbx2 protein expression. Immunostaining was evaluated by two breast pathologists from the The 


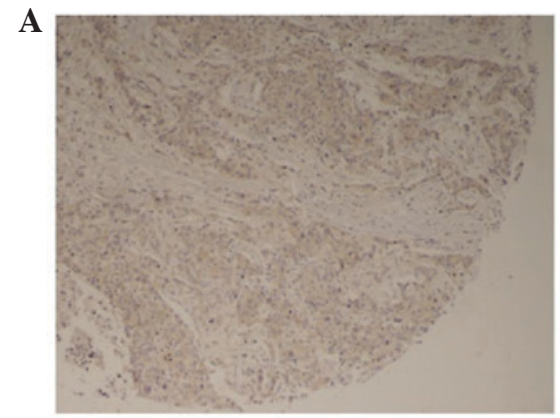

D

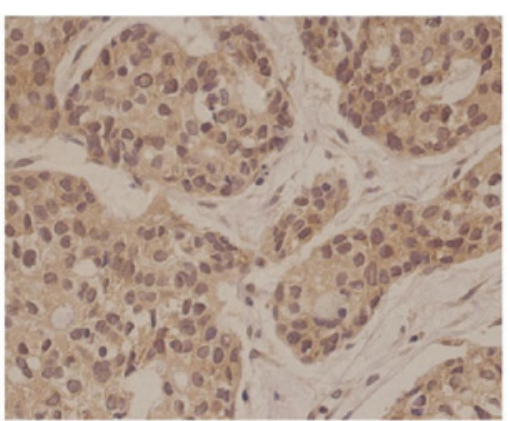

B

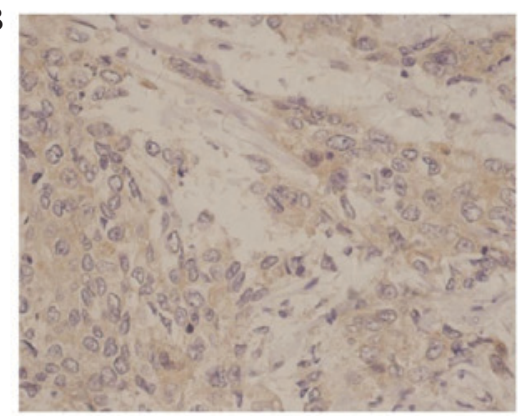

$\mathbf{E}$

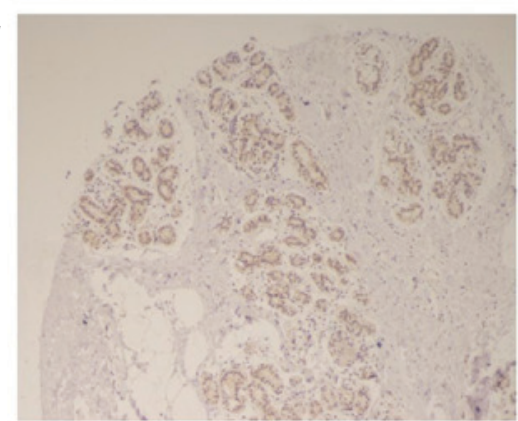

C

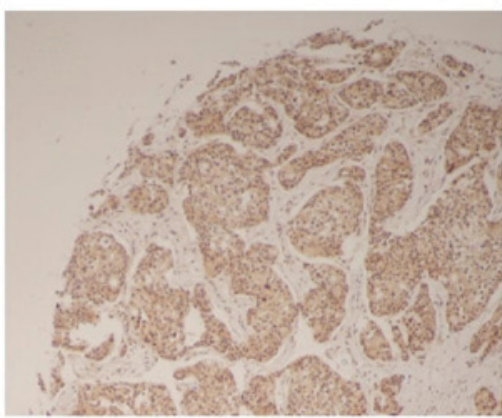

$\mathbf{F}$

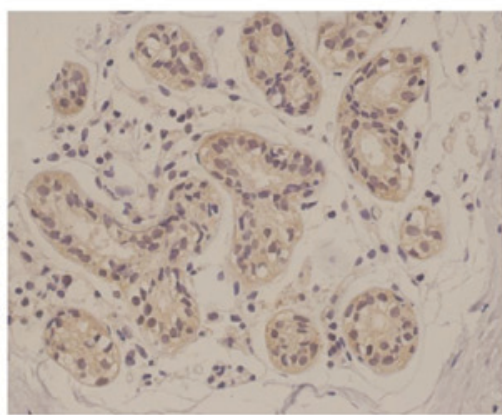

Figure 1. Immunohistochemical staining of $\mathrm{Cbx} 2$ in the normal breast and breast cancer tissues. (A) Low cytoplasmic Cbx 2 expression in normal breast tissues (magnification, x100). (B) Low cytoplasmic Cbx 2 expression in normal breast tissues (magnification, x400). (C) Low cytoplasmic Cbx 2 expression in the specimens (magnification, x100). (D) Low cytoplasmic Cbx 2 expression in the specimens (magnification, $\mathrm{x} 400$ ). (E) High cytoplasmic Cbx2 expression in cancer tissues (magnification, x100). (F) High cytoplasmic Cbx2 expression in cancer tissues (magnification, x400). Cbx2, chromobox2.

Affiliated Tumor Hospital of Harbin Medical University, who were blinded to the patient clinical outcomes. Scoring was performed using the semi-quantitative score method (25) to calculate the product of the percentage and intensity of positively stained tumor cells within the invasive tissue component. In the cytoplasm, staining intensity was graded as follows: 0, no staining; 1, weak staining (light yellow); 2 , moderate staining (yellow brown); and 3, strong staining (brown). The percentage (0-100\%) of staining was scored as follows: 0 , no positive tumor cells; $1,<25 \%$ positive tumor cells; $2,25-50 \%$ positive tumor cells; $3,51-75 \%$ positive tumor cells; and $5,>75 \%$ positive tumor cells $(25,26)$. The immunoreactive score (IRS) ranged between 0 and 12. An IRS score (IRS $=$ staining percentage $\mathrm{x}$ staining intensity) of $<6$ was classified as low expression, whereas a score of $>6$ indicated high expression.

Follow-up. All patients were advised to attend follow-up examinations every 4-6 months for the first 5 years following surgery, and every 12 months thereafter. All patients were regularly followed up until mortality or the study end date (30 December, 2012). Prognosis was recorded by the Center of Medical Records at The Affiliated Tumor Hospital of Harbin Medical University. Overall survival (OS) time was assessed for prognostic analysis.

Statistical and survival analyses. All statistical analyses were performed using SPSS 13.0 statistical software (SPSS, Inc., Chicago, IL, USA). The difference in Cbx 2 expression between breast cancer tissues and normal tissues was assessed using the Mann-Whitney U test. The association between Cbx 2 and patient clinicopathological features was analyzed using the $\chi^{2}$ test. OS time was determined as the time from surgery to the date of mortality or last follow-up. Kaplan-Meier analysis was used to estimate OS time. Univariate analysis was performed using the log-rank test. Univariate and multivariate Cox proportional hazard models were used to assess clinicopathological prognostic factors affecting OS. $\mathrm{P}<0.05$ was considered to indicate a statistically significant difference.

\section{Results}

Cbx2 protein expression in cancer and normal breast tissues. $\mathrm{Cbx} 2$ expression was identified in the cytoplasm of breast cancer tissues (Fig. 1). Cbx2 expression was also identified in the cytoplasm of matched adjacent normal tissues (Fig. 1A and B). Representative immunohistochemical images demonstrate low and high Cbx2 expression (Fig. 1C-F).

A total of 216 paired cancer tissues and matched adjacent normal tissues were obtained for analysis. Cbx2 protein expression was identified in 199/216 tumor tissues and 196/216 adjacent tissues. Notably, in 15 (6.94\%) paired cancer and adjacent normal tissues, $\mathrm{Cbx} 2$ expression was higher in normal tissues compared with cancer tissues. However, in 175 (81.01\%) normal tissues, Cbx2 expression was lower compared with in cancer tissues. A total of $26(12.04 \%)$ paired tissues exhibited equal $\mathrm{Cbx} 2$ expression. The median and mean IRS of 455 tumor tissues were 6.00 and 6.21, respectively, whereas the median and mean IRS of the 216 matched normal adjacent tissues were 3.00 and 3.48, respectively. The protein expression of Cbx2 was significantly higher in tumor tissues compared with adjacent normal tissues $(\mathrm{P}<0.001)$. Using an IRS of 6 as the cut-off value for high $\mathrm{Cxb} 2$ expression, $53.89 \%$ (245/416) tumor tissues and $11.11 \%(24 / 216)$ adjacent normal tissues exhibited high Cbx2 expression $(\mathrm{P}<0.001)$. 
Table I. Association between Cbx2 expression and patient clinicopathological features.

\begin{tabular}{|c|c|c|c|c|}
\hline \multirow[b]{2}{*}{ Parameter } & \multirow[b]{2}{*}{$\mathrm{n}$} & \multicolumn{2}{|c|}{ Cbx 2 expression } & \multirow[b]{2}{*}{ P-value } \\
\hline & & Low, n (\%) & High, n (\%) & \\
\hline Age, years & & & & 0.441 \\
\hline$<50$ & 249 & $119(47.8)$ & $130(52.2)$ & \\
\hline$\geq 50$ & 206 & $91(44.2)$ & $115(55.8)$ & \\
\hline Tumor size, $\mathrm{cm}$ & & & & $<0.001$ \\
\hline$<2$ & 101 & $65(64.4)$ & $36(35.6)$ & \\
\hline$\geq 2$ & 353 & $144(40.8)$ & 209 (59.2) & \\
\hline Pathological stage & & & & 0.286 \\
\hline I & 40 & $23(57.5)$ & $17(42.5)$ & \\
\hline II & 121 & $56(46.3)$ & $65(53.7)$ & \\
\hline III & 285 & $126(44.2)$ & $159(55.8)$ & \\
\hline LNM & & & & 0.008 \\
\hline Negative & 210 & $111(52.9)$ & $99(47.1)$ & \\
\hline Positive & 245 & $99(40.4)$ & $146(59.6)$ & \\
\hline TNM stage & & & & $<0.001$ \\
\hline I & 91 & $75(82.4)$ & $16(17.6)$ & \\
\hline II & 225 & $131(58.2)$ & $94(41.8)$ & \\
\hline III & 139 & $4(2.9)$ & $135(97.1)$ & \\
\hline $\mathrm{Ki}-67, \%$ & & & & 0.080 \\
\hline$<10$ & 147 & $77(52.4)$ & $70(47.6)$ & \\
\hline$\geq 10$ & 305 & $133(43.6)$ & $172(56.4)$ & \\
\hline HER-2 status & & & & 0.048 \\
\hline Negative & 363 & $176(48.5)$ & 187 (51.5) & \\
\hline Positive & 92 & $34(37.0)$ & $58(63.0)$ & \\
\hline ER status & & & & 0.162 \\
\hline Negative & 242 & $104(43.0)$ & $138(57.0)$ & \\
\hline Positive & 212 & 105 (49.5) & $107(50.5)$ & \\
\hline PR status & & & & 0.174 \\
\hline Negative & 180 & $76(42.2)$ & $104(57.8)$ & \\
\hline Positive & 275 & $134(48.7)$ & $141(51.3)$ & \\
\hline p53 status & & & & 0.717 \\
\hline Negative & 79 & $35(44.3)$ & $44(55.7)$ & \\
\hline Positive & 376 & 175 (46.5) & $201(53.5)$ & \\
\hline Subtype & & & & 0.388 \\
\hline HER-2 & 92 & $37(40.2)$ & $55(59.8)$ & \\
\hline Luminal A & 85 & $44(51.8)$ & $41(48.2)$ & \\
\hline Luminal B & 234 & $111(47.4)$ & $123(52.6)$ & \\
\hline Triple negative & 44 & $18(40.9)$ & $26(59.1)$ & \\
\hline
\end{tabular}

Cbx2, chromobox2; LNM, lymph node metastasis; TNM, tumor node metastasis; HER-2, human epidermal growth factor-2; ER, estrogen receptor; PR, progesterone receptor; $\mathrm{p} 53$, tumor protein 53 .

Association between Cbx2 protein expression and patient clinicopathological features. A total of 455 tumor tissues were included in the present study. The median IRS of Cbx 2 expression was 6 , which was used as a cut-off for high expression. Based on this cut-off value, $46.15 \%(210 / 455)$ and $53.85 \%(245 / 455)$ tumor tissues exhibited low and high Cbx 2 cytoplasmic expression, respectively. The expression of cytoplasmic $\mathrm{Cbx} 2$ was found to significantly associate with tumor size $(\mathrm{P}<0.001)$, lymph node metastasis $(\mathrm{P}=0.008)$, tumor node metastasis (TNM) classification of malignant tumors (18) stage $(\mathrm{P}<0.001)$ and positive HER-2 status $(\mathrm{P}=0.048)$ (Table I).

Association between Cbx2 expression and prognosis of patients with breast cancer. A total of 403 patients were 
Table II. Univariate and multivariate cox regression analyses of overall survival time in breast cancer patients.

\begin{tabular}{|c|c|c|c|c|c|c|}
\hline \multirow[b]{2}{*}{ Parameter } & \multicolumn{3}{|c|}{ Univariate analysis } & \multicolumn{3}{|c|}{ Multivariate analysis } \\
\hline & HR & $95 \% \mathrm{CI}$ & P-value & HR & $95 \% \mathrm{CI}$ & P-value \\
\hline Tumor size, $\mathrm{cm}(\geq 2 /<2)$ & 2.361 & $1.074-5.189$ & 0.033 & 1.231 & $0.542-2.795$ & 0.619 \\
\hline Pathological stage (I/II/III) & 1.778 & $1.095-2.888$ & 0.020 & 1.399 & $0.838-2.336$ & 0.199 \\
\hline TNM stage (positive/negative) & 3.671 & $1.989-6.777$ & $<0.001$ & 3.427 & $1.363-8.614$ & 0.009 \\
\hline LNM (positive/negative) & 3.069 & $2.006-4.696$ & $<0.001$ & 1.025 & $0.389-2.699$ & 0.960 \\
\hline Ki-67 status (positive/negative) & 1.920 & $1.040-3.545$ & 0.037 & 1.673 & $0.866-3.233$ & 0.126 \\
\hline PR status (positive/negative) & 0.579 & $0.350-0.956$ & 0.033 & 0.878 & $0.333-2.314$ & 0.792 \\
\hline \multicolumn{7}{|l|}{ Subtype } \\
\hline HER-2 status (positive/negative) & Reference & & & Reference & & \\
\hline Luminal A & 0.878 & $0.433-1.781$ & 0.718 & 1.264 & $0.409-3.909$ & 0.684 \\
\hline Luminal B & 0.488 & $0.259-0.919$ & 0.026 & 0.698 & $0.250-1.948$ & 0.493 \\
\hline Triple negative & 1.108 & $0.478-2.569$ & 0.810 & 1.608 & $0.677-3.823$ & 0.282 \\
\hline Cbx2 expression (high/low) & 1.826 & $1.069-3.116$ & 0.027 & 1.790 & $1.048-3.056$ & 0.236 \\
\hline
\end{tabular}

HR, hazard ratio; CI, confidence interval; ER, estrogen receptor; PR, progesterone receptor; HER-2, human epidermal growth factor-2; p53, tumor protein 53; Cbx2, chromobox 2 .

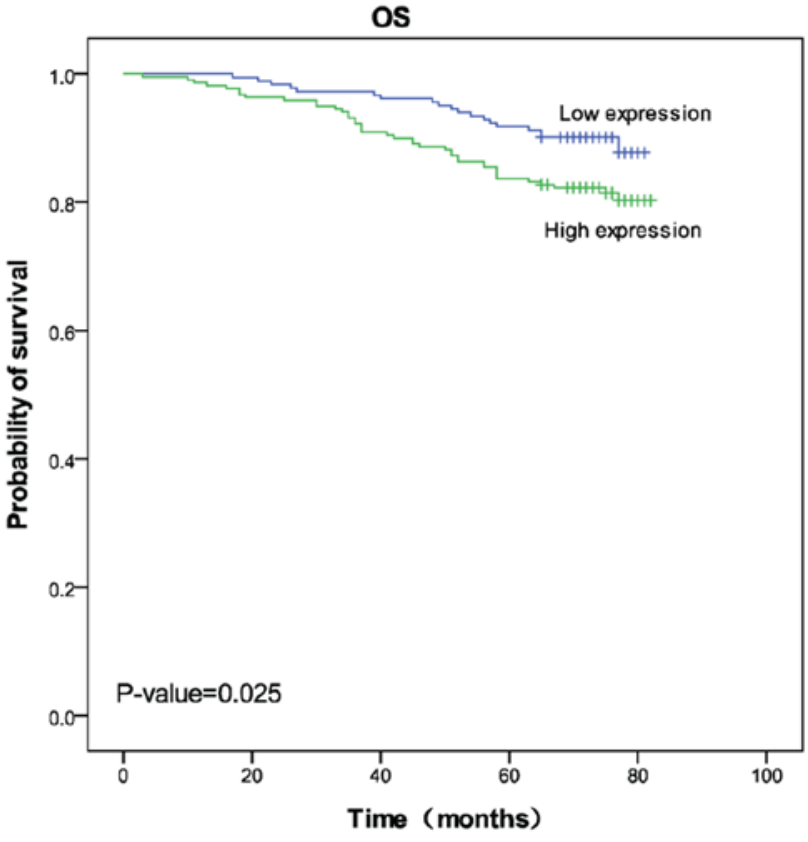

Figure 2. Kaplan-Meier survival analysis revealed high expression of chromobox 2 indicates poor overall survival in patients with breast cancer. OS, overall survival.

followed up and 52 patients were lost to follow-up. During the follow-up period, $10.93 \%$ (20/183) and $18.64 \%(41 / 220)$ patients in the low and high $\mathrm{Cbx} 2$ expression groups succumbed to the disease, respectively. The mean survival times were 77.37 months (range, 75.66-79.07 months) and 74.29 months (range, 71.94-76.64 months) in the low and high Cbx 2 expression groups, respectively. Kaplan-Meier 5-year survival curves were stratified for $\mathrm{Cbx} 2$ expression and the results revealed that high Cbx 2 expression was associated with poor prognosis (log-rank test statistic, 5.032; $\mathrm{P}=0.025 ;$ Fig. 2).
Univariate and multivariate Cox regression analyses were performed to evaluate the association between $\mathrm{Cbx} 2$ expression and clinicopathological features on patient prognosis. Variables such as tumor size, pathological stage, lymph node metastasis, TNM stage, Ki-67 status, PR status and molecular subtype were included in multivariate analyses, which were associated with survival of patients with breast cancer as identified by the log-rank test. Univariate Cox analysis demonstrated significantly shorter OS time in patients with a large tumor size [(hazard ratio (HR), 2.361; 95\% confidence interval $(\mathrm{CI}), 1.074-5.189 ; \mathrm{P}=0.033$ ], positive $\mathrm{PR}$ status (HR, 0.579; 95\% CI, 0.350-0.956; $\mathrm{P}=0.033$ ), positive Ki-67 status (HR, 1.920; 95\% CI, 1.040-3.545; P=0.037) and high Cbx2 expression (HR, 1.826; 95\% CI, 1.069-3.116; $\mathrm{P}=0.027$ ) (Table II). The multivariate Cox proportional hazard model revealed that only high TNM stage (HR=3.427; 95\% $\mathrm{CI}=1.363-8.614 ; \mathrm{P}=0.009)$ was independently associated with poor survival (Table II).

Effect of Taxol in patients expressing Cbx2. A total of 309 patients underwent chemotherapy treatment. Among these patients, 122 received Taxol and 187 received an alternative chemotherapy regimen without Taxol (including nedaplatin cis-platinum, nedaplatin fluorouracil, nedaplatin epirubicin and fluorouracil epirubicin cyclophosphamide). Among patients with high Cbx2 expression, the mean OS time of patients receiving Taxol treatment (71.01 months) was significantly shorter compared with patients receiving treatment without Taxol (78.43 months) $(\mathrm{P}<0.001)$. However, in the low Cbx 2 expression group, no significant difference in the mean OS time of patients was identified between those treated with Taxol (76.45 months) and those without Taxol treatment (78.41 months) $(\mathrm{P}=0.296)$. These results indicated that patients with high $\mathrm{Cbx} 2$ expression do not exhibit sensitivity to chemotherapy programs that include Taxol (Fig. 3). 
A

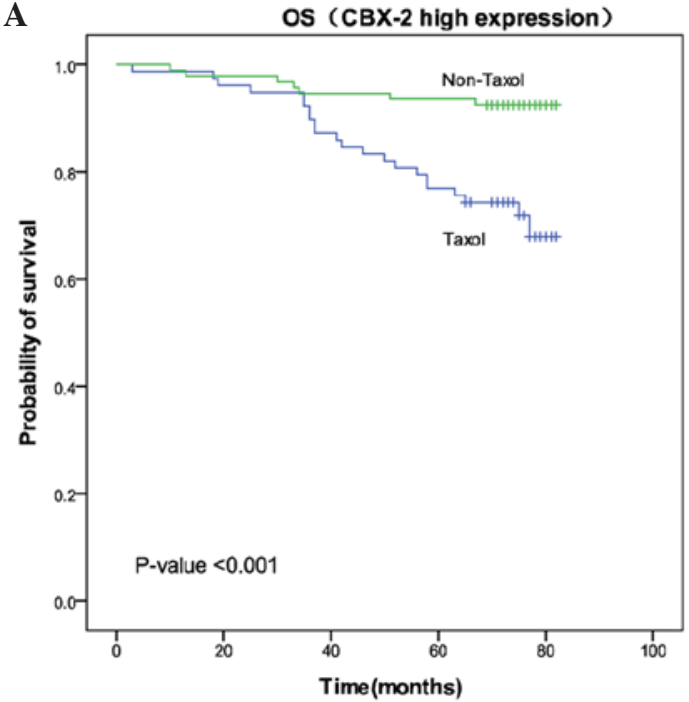

B

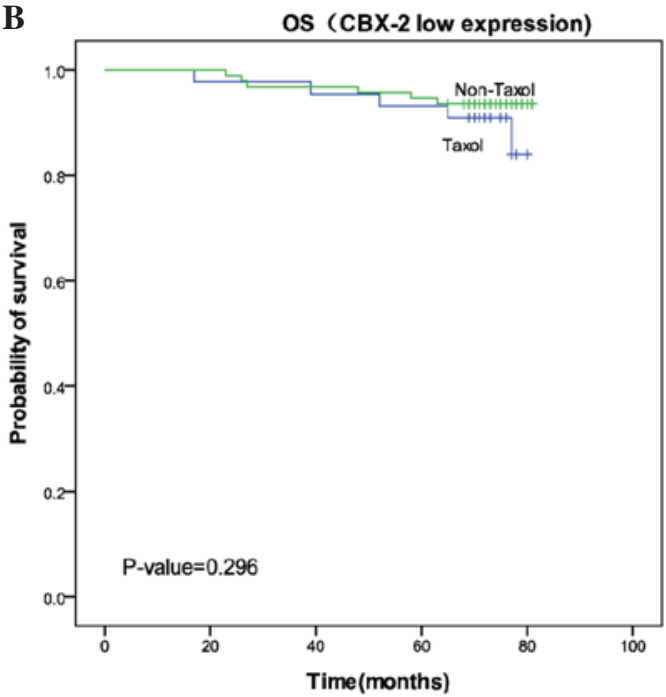

Figure 3. Kaplan-Meier survival analysis curves showing OS times of breast cancer patients in the (A) high and (B) low Cbx 2 expression groups, treated with or without Taxol. OS, overall survival; Cbx2, chromobox2.

\section{Discussion}

The results of the present study demonstrated that breast cancer tissues exhibited higher levels of $\mathrm{Cbx} 2$ expression compared with normal tissues (53.85 vs. 11.11\%). Aberrant expression of $\mathrm{Cbx} 2$ at the mRNA level has been observed in colon, breast, stomach and lung cancer (27). In the present study, $\mathrm{Cbx} 2$ protein expression was associated with certain clinicopathological features in breast cancer patients. High Cbx 2 expression was found to associate with a large tumor size $(\mathrm{P}<0.001)$, and this finding was consistent with the results of a previous oral squamous cell carcinoma study (28). In addition, Cbx 2 was significantly associated with lymph node metastasis $(\mathrm{P}=0.008)$ and a positive HER-2 status $(\mathrm{P}=0.048)$. A positive association was also identified between $\mathrm{Cbx} 2$ expression and TNM stage $(\mathrm{P}<0.001)$. At present, the function of $\mathrm{Cbx} 2$ in tumorigenesis remains unclear, however emerging evidence has indicated that the $\mathrm{Cbx} 2$ protein exhibits a critical role in cancer initiation and progression $(29,30)$.

Cbx2 is a primary member of the Cbx protein family, and is a component of the PRC1 complex that regulates chromatin. PRC1 exhibits enzymatic activity to modify histones and repress the transcription of target genes $(31,32)$. The ability of PRC1 to promote proliferation may be associated with PcG activity in cancer (33). The $\mathrm{Cbx} 2$ protein is a major component involved in the recruitment of PRC1 proteins to mitotic chromosomes (34). Cbx 2 also directly regulates the expression of the cyclin-dependent kinase inhibitor, p21, and dominantly controls the expression of the INK4A/ARF locus, which is extremely important for human hematopoietic cell proliferation (35). The overexpression of $\mathrm{Cbx} 2$ results in the differentiation and exhaustion of hematopoietic stem cells (16). Previous studies regarding the mechanism of $\mathrm{Cbx} 2$ in regulating hematological stem cell differentiation have been conducted, however, few studies have investigated the function of Cbx 2 in solid tumors $(16,36)$. The present study provides a basis for future functional studies to identify molecular mechanisms by which $\mathrm{Cbx} 2$ may promote tumor initiation and progression.

The current study indicated that $\mathrm{Cbx} 2$ expression associates with the prognosis of breast cancer patients. At the final follow-up, the mortality rates in the high and low Cbx2 expression groups were 18.64 and $10.93 \%$, respectively. The mean survival time in the high $\mathrm{Cbx} 2$ expression group (74.29 months) was significantly shorter than that in the low expression group (77.37 months). High Cbx 2 expression was also significantly associated with poor OS (HR, 1.826; 95\% CI, 1.069-3.116; $\mathrm{P}=0.027)$. Considering the poor prognosis of patients with high $\mathrm{Cbx} 2$ expression, we hypothesize that $\mathrm{Cbx} 2$ may present an important predictor of breast cancer prognosis. By integrating multiple platforms on several biological levels, Clermont et al (27) demonstrated that an increased Cbx2 copy number associates with increased $\mathrm{Cbx} 2$ expression, which is significantly associated with poor OS. Due to the heterogeneity observed in the progression and outcome of breast cancer, the identification of more predictive biomarkers is required to guide clinical treatment.

Taxol is a microtubule-stabilizing drug approved by the Food and Drug Administration for the treatment of breast cancer (37). A previous study revealed that breast cancer patients that received nab-paclitaxel neoadjuvant chemotherapy exhibited a pathological complete response rate of $48.1 \%$ (38). Despite the high response rate, certain patients exhibit low or no response to Taxol. Thus, additional effective biomarkers are required to identify which patients would benefit from Taxol therapy. In the current study, the OS time of patients treated with Taxol was significantly lower than that of patients who did not receive Taxol treatment in the high Cbx 2 expression group. However, no significant difference in OS time was identified between patients treated with or without Taxol in the low $\mathrm{Cbx} 2$ expression group. The association between Cbx 2 expression and survival of breast cancer patients treated with fluorouracil was also analyzed in the present study. No significant difference was identified between the OS time of patients with and without fluorouracil 
treatments in the high or low $\mathrm{Cbx} 2$ expression groups (data not provided). Thus, Cbx 2 may present a specific biomarker for Taxol resistance in breast cancer patients. Numerous studies have been conducted to identify marker resistance or sensitivity to Taxol. These studies identified various candidates, including adenosine triposphate-binding cassette subfamily $\mathrm{C}$ member10, microRNA and solute carrier genes (39-41). However, these studies did not identify a validated biomarker to predict which patients would benefit from Taxol therapy. $\mathrm{Cbx} 2$ may present a promising indicator for predicting the use of Taxol in breast cancer chemotherapy. However, further clinical studies are required to verify these results.

The present study demonstrated the association between Cbx 2 expression and breast cancer. However, certain points require further study. Firstly, dynamic localization of the nuclear-cytoplasmic and/or sub-nuclear distribution of members of the Cbx family occurs during the maternal-to-embryonic transition (42). The present study revealed that $\mathrm{Cbx} 2$ was predominantly expressed in the cytoplasm. Nuclear proteins under normal conditions are frequently overexpressed in the cytoplasm in various human cancers, including hepatocellular carcinoma, melanoma, papillary thyroid carcinoma and ductal breast carcinoma $(43,44)$. Secondly, tumorigenesis is a dynamic evolutionary process that promotes genetic heterogeneity and produces a complex combination of random and nonrandom aberrations. The current study investigated $\mathrm{Cbx} 2$ expression at the protein level and thus, results must be confirmed by integrating multiple platforms on several biological levels (DNA-RNA-protein). Thirdly, all samples in the current study were recruited from a single hospital. Due to the heterogeneity of breast cancer, future studies which include individuals of different ethnicities in the patient cohort are required to validate the results of the present study. Furthermore, studies which aim to elucidate the molecular mechanisms underlying $\mathrm{Cbx} 2$ protein expression and its function in tumorigenesis are required.

In conclusion, in the present study $\mathrm{Cbx} 2$ protein expression levels were inversely associated with prognosis in breast cancer patients. Cbx 2 expression was associated with clinical features, including positive lymph node metastasis status, large tumor size and positive HER-2 status. Therefore, Cbx2 may present a novel biomarker for the selection of an appropriate chemotherapy regimen for breast cancer patients.

\section{References}

1. Siegel R, Ma J, Zou Z and Jemal A: Cancer statistics, 2014. CA Cancer J Clin 64: 9-29, 2014

2. DeSantis C, Ma J, Bryan L and Jemal A: Breast cancer statistics, 2013. CA Cancer J Clin 64: 52-62, 2014.

3. Ali AM, Provenzano E, Bartlett JM, Abraham J, Driver K, Munro AF, Twelves C, Poole CJ, Hiller L, Dunn JA, et al: Prognosis of early breast cancer by immunohistochemistry defined intrinsic sub-types in patients treated with adjuvant chemotherapy in the NEAT/BR9601 trial. Int J Cancer 133: 1470-1478, 2013.

4. Liu R, Lv QL, Yu J, Hu L, Zhang LH, Cheng Y and Zhou HH: Correlating transcriptional networks with pathological complete response following neoadjuvant chemotherapy for breast cancer. Breast Cancer Res Treat 151: 607-618, 2015.

5. Krishnan P, Ghosh S, Wang B, Li D, Narasimhan A, Berendt R, Graham K, Mackey JR, Kovalchuk O and Damaraju S: Next generation sequencing profiling identifies miR-574-3p and miR-660-5p as potential novel prognostic markers for breast cancer. BMC Genomics 16: 735, 2015.
6. Boccardo F, Rubagotti A, Nuzzo PV, Argellati F, Savarino G, Romano P,Damonte G, Rocco M and Profumo A: Matrix-assisted laser desorption/ionisation (MALDI) TOF analysis identifies serum angiotensin II concentrations as a strong predictor of all-cause and breast cancer (BCa)-specific mortality following breast surgery. Int J Cancer 137: 2394-2402, 2015.

7. Sparmann A and van Lohuizen M: Polycomb silencers control cell fate, development and cancer. Nat Rev Cancer 6: 846-856, 2006.

8. Shao Z, Raible F, Mollaaghababa R, Guyon JR, Wu CT, Bender W and Kingston RE: Stabilization of chromatin structure by PRC1, a Polycomb complex. Cell 98: 37-46, 1999.

9. Levine SS, Weiss A, Erdjument-Bromage H, Shao Z, Tempst P and Kingston RE: The core of the polycomb repressive complex is compositionally and functionally conserved in flies and humans. Mol Cell Biol 22: 6070-6078, 2002.

10. Kuzmichev A, Nishioka K, Erdjument-Bromage H, Tempst P and Reinberg D: Histone methyltransferase activity associated with a human multiprotein complex containing the Enhancer of Zeste protein. Genes Dev 16: 2893-2905, 2002.

11. Vincenz C and Kerppola TK: Different polycomb group CBX family proteins associate with distinct regions of chromatin using nonhomologous protein sequences. Proc Natl Acad Sci USA 105: 16572-16577, 2008

12. Shinjo K, Yamashita Y, Yamamoto E, Akatsuka S, Uno N, Kamiya A, Niimi K, Sakaguchi Y, Nagasaka T, Takahashi T, et al: Expression of chromobox homolog 7 (CBX7) is associated with poor prognosis in ovarian clear cell adenocarcinoma via TRAIL-induced apoptotic pathway regulation. Int J Cancer 135: 308-318, 2014.

13. Scott CL, Gil J, Hernando E, Teruya-Feldstein J, Narita M, Martínez D, Visakorpi T, Mu D, Cordon-Cardo C, Peters G, et al: Role of the chromobox protein CBX7 in lymphomagenesis. Proc Natl Acad Sci USA 104: 5389-5394, 2007.

14. Zhang XW, Zhang L, Qin W, Yao XH, Zheng LZ, Liu X, Li J and Guo WJ: Oncogenic role of the chromobox protein CBX7 in gastric cancer. J Exp Clin Cancer Res 29: 114, 2010.

15. Li J, Xu Y, Long XD, Wang W, Jiao HK, Mei Z, Yin QQ, Ma LN, Zhou AW, Wang LS, et al: Cbx4 governs HIF-1 $\alpha$ to potentiate angiogenesis of hepatocellular carcinoma by its SUMO E3 ligase activity. Cancer Cell 25: 118-131, 2014.

16. Klauke K, Radulović V, Broekhuis M, Weersing E, Zwart E, Olthof S, Ritsema M, Bruggeman S, Wu X, Helin K, et al: Polycomb Cbx family members mediate the balance between haematopoietic stem cell self-renewal and differentiation. Nat Cell Biol 15: 353-362, 2013

17. Parris TZ, Danielsson A, Nemes S, Kovács A, Delle U, Fallenius G, Möllerström E, Karlsson P and Helou K: Clinical implications of gene dosage and gene expression patterns in diploid breast carcinoma. Clin Cancer Res 16: 3860-3874, 2010.

18. Lakhani SR, Ellis IO, Schnitt SJ, Tan PH and van de Vijver MJ (eds). WHO Classification of Tumours of the Breast. 4th edition. IARC, WHO, 2012.

19. Nishimukai A, YagiT, Yanai A,Miyagawa Y,Enomoto Y,Murase K, Imamura M, Takatsuka Y, Sakita I, Hatada T and Miyoshi Y: High Ki-67 expression and low progesterone receptor expression could independently lead to a worse prognosis for postmenopausal patients with estrogen receptor-positive and HER2-negative breast cancer. Clin Breast Cancer 15: 204-211, 2015.

20. Wolff AC, Hammond ME, Hicks DG, Dowsett M, McShane LM, Allison KH, Allred DC, Bartlett JM, Bilous M, Fitzgibbons P, et al American Society of Clinical Oncology; College of American Pathologists: Recommendations for human epidermal growth factor receptor 2 testing in breast cancer: American Society of Clinical Oncology/College of American Pathologists clinical practice guideline update. Arch Pathol Lab Med 138: 241-256, 2014

21. Tubbs RR, Hicks DG, Cook J, Downs-Kelly E, Pettay J, Hartke MB, Hood L, Neelon R, Myles J, Budd GT, et al: Fluorescence in situ hybridization (FISH) as primary methodology for the assessment of HER2 Status in adenocarcinoma of the breast: A single institution experience. Diagn Mol Pathol 16: 207-210, 2007.

22. Falato C, Lorent J, Tani E, Karlsson E, Wright PK, Bergh J and Foukakis T: Ki67 measured in metastatic tissue and prognosis in patients with advanced breast cancer. Breast Cancer Res Treat 147: 407-414, 2014.

23. Millar EK, Graham PH, McNeil CM, Browne L, O'Toole SA, Boulghourjian A, Kearsley JH, Papadatos G, Delaney G, Fox C, et al: Prediction of outcome of early ER+ breast cancer is improved using a biomarker panel, which includes $\mathrm{Ki}-67$ and p53. Br J Cancer 105: 272-280, 2011. 
24. Yamashita H, Toyama T, Nishio M, Ando Y, Hamaguchi M, Zhang Z, Kobayashi S, Fujii Y and Iwase H: p53 protein accumulation predicts resistance to endocrine therapy and decreased post-relapse survival in metastatic breast cancer. Breast Cancer Res 8: R48, 2006.

25. Remmele W and Stegner HE: Recommendation for uniform definition of an immunoreactive score (IRS) for immunohistochemical estrogen receptor detection (ER-ICA) in breast cancer tissue. Pathologe 8: 138-140, 1987 (In German).

26. Remmele W and Schicketanz KH: Immunohistochemical determination of estrogen and progesterone receptor content in human breast cancer. Computer-assisted image analysis (QIC score) vs subjective grading (IRS). Pathol Res Pract 189: 862-866, 1993.

27. Clermont PL, Sun L, Crea F, Thu KL, Zhang A, Parolia A, Lam WL and Helgason CD: Genotranscriptomic meta-analysis of the Polycomb gene CBX2 in human cancers: Initial evidence of an oncogenic role. Br J Cancer 111: 1663-1672, 2014.

28. Parris TZ, Aziz L, Kovács A, Hajizadeh S, Nemes S, Semaan M, Chen CY, Karlsson P and Helou K: Clinical relevance of breast cancer-related genes as potential biomarkers for oral squamous cell carcinoma. BMC Cancer 14: 324, 2014.

29. Satijn DP, Olson DJ, van der Vlag J, Hamer KM, Lambrechts C, Masselink H, Gunster MJ, Sewalt RG, van Driel R and Otte AP: Interference with the expression of a novel human polycomb protein $\mathrm{hPc} 2$, results in cellular transformation and apoptosis. Mol Cell Biol 17: 6076-6086, 1997.

30. Jiang Y, Malouf GG, Zhang J, Zheng X, Chen Y, Thompson EJ, Weinstein JN, Yuan Y, Spano JP, Broaddus R, et al: Long non-coding RNA profiling links subgroup classification of endometrioid endometrial carcinomas with trithorax and polycomb complex aberrations. Oncotarget 6: 39865-39876, 2015.

31. Kerppola TK: Polycomb group complexes-many combinations, many functions. Trends Cell Biol 19: 692-704, 2009.

32. Di Croce L and Helin K: Transcriptional regulation by Polycomb group proteins. Nat Struct Mol Biol 20: 1147-1155, 2013.

33. Piunti A, Rossi A, Cerutti A, Albert M, Jammula S, Scelfo A, Cedrone L, Fragola G, Olsson L, Koseki H, et al: Polycomb proteins control proliferation and transformation independently of cell cycle checkpoints by regulating DNA replication. Nat Commun 5: 3649, 2014.

34. Zhen CY, Duc HN, Kokotovic M, Phiel CJ and Ren X: Cbx2 stably associates with mitotic chromosomes via a PRC2- or PRC1-independent mechanism and is needed for recruiting PRC1 complex to mitotic chromosomes. Mol Biol Cell 25: 3726-3739, 2014.
35. van den Boom V, Rozenveld-Geugien M, Bonardi F, Malanga D, van Gosliga D, Heijink AM, Viglietto G, Morrone G, Fusetti F, Vellenga E and Schuringa JJ: Nonredundant and locus-specific gene repression functions of PRC1 paralog family members in human hematopoietic stem/progenitor cells. Blood 121: 2452-2461, 2013.

36. van den Boom V, Rozenveld-Geugien M, Bonardi F, Malanga D, van Gosliga D, Heijink AM, Viglietto G, Morrone G, Fusetti F, Vellenga E and Schuringa JJ: Nonredundant and locus-specific gene repression functions of PRC1 paralog family members in human hematopoietic stem/progenitor cells. Blood 121: 2452-2561, 2013.

37. Weaver BA: How Taxol/paclitaxel kills cancer cells. Mol Biol Cell 25: 2677-2681, 2014.

38. Zelnak AB, Nikolinakos P, Srinivasiah J, Jonas W, Pippas A, Liu Y, Li X, Torres M and O'Regan RM; Georgia Center for Oncology Research and Education: High pathologic complete response in Her2-positive, early-stage breast cancer to a novel nonanthracycline neoadjuvant chemotherapy. Clin Breast Cancer 15: 31-36, 2015.

39. Kathawala RJ, Sodani K, Chen K, Patel A, Abuznait AH, Anreddy N, Sun YL, Kaddoumi A, Ashby CR Jr and Chen ZS: Masitinib antagonizes ATP-binding cassette subfamily C member 10-mediated paclitaxel resistance: A preclinical study. Mol Cancer Ther 13: 714-723, 2014.

40. Peng X, Cao P, He D, Han S, Zhou J, Tan G, Li W, Yu F, Yu J, Li Z and Cao K: MiR-634 sensitizes nasopharyngeal carcinoma cells to paclitaxel and inhibits cell growth both in vitro and in vivo. Int J Clin Exp Pathol 7: 6784-6791, 2014.

41. Russell P, Hennessy BT, Li J, Carey MS, Bast RC, Freeman T and Venkitaraman AR: Cyclin G1 regulates the outcome of taxane-induced mitotic checkpoint arrest. Oncogene 31: 2450-2460, 2012.

42. Ruddock-D'Cruz NT, Prashadkumar S, Wilson KJ, Heffernan C, Cooney MA, French AJ, Jans DA, Verma PJ and Holland MK: Dynamic changes in localization of Chromobox (Cbx) family members during the maternal to embryonic transition. Mol Reprod Dev 75: 477-488, 2008.

43. Huynh H: Overexpression of tumour suppressor retinoblastoma 2 protein (pRb2/p130) in hepatocellular carcinoma. Carcinogenesis 25: 1485-1494, 2004.

44. Reno EM, Haughian JM, Dimitrova IK, Jackson TA, Shroyer KR and Bradford AP: Analysis of protein kinase C delta (PKC delta) expression in endometrial tumors. Hum Pathol 39: 21-29, 2008 